\title{
CRITICAS DE CIERTOS AUTORES QUE HAN CONSIDERADO A LA MUJER UN OBJETO DE PIEDAD, CASI DE MENOSPRECIO *
}

\section{Mary Wollstonecraft}

Quedan ahora por examinar las opiniones que sobre el carácter de la mujer y de su educación, se han expuesto en algunas publicaciones modernas y que dan el tono de la mayoría de las observaciones realizadas precipitadamente sobre el sexo.

\section{PARTE I}

Empezaré con Rousseau y, basándome en sus propias palabras, presentaré un boceto de su opinión sobre el carácter de la mujer, intercalando comentarios y reflexiones. Cierto es que mis comentarios brotarán de unos pocos y sencillos principios, que pueden deducirse de cuanto ya he dicho, pero la estructura artificial de Rousseau ha sido construida con tanto ingenio que se me hace necesario atacarla de una manera más minuciosa, y realizar yo misma su estudio.

Sofía, dice Rousseau, debiera ser a la mujer lo que en perfección es Emilio al hombre, y, para llegar a ello, es necesario examinar el carácter que la naturaleza ha dado a su sexo.

Procede entonces a demostrar que la mujer debe ser débil y pasiva,

* Capítulo V de Vindicación de los derecbos de la mujer, Tribuna Feminista, Ed. Debate, Madrid, 1977. 
porque posee una fuerza corporal menor que el hombre; y de ahí deduce que ha sido creada para proporcionarle placer y someterse a él, y que su deber es ofrecerse a su dueño como un ser grato, siendo éste el gran fin de su existencia ${ }^{1}$. No obstante, para cubrir con un ridículo manto de dignidad a la lujuria, insiste en que el hombre no ha de servirse de su fuerza cuando busca el placer, sino que debe someterse a los deseos de ella.

«De aquí deducimos una tercera consecuencia de la distinta constitución de los sexos y es que el más fuerte debiera, en apariencia, ser el dueño y depender, de hecho del más débil; y esto es así, no por una utilización frívola de la galantería, la vanidad y el espíritu de protección, sino por una ley inmutable de la naturaleza, la cual, favoreciendo a la mujer con una mayor facilidad para excitar deseos que al hombre para satisfacerlos, convierte a este último en un ser dependiente de la primera en lo que respecta al placer, y le incita a esforzarse en proporcionárselo en contrapartida, para obtener su consentimiento de que él es el más fuerte ${ }^{2}$. En estas ocasiones, la circunstancia más deliciosa que el hombre encuentra en su victoria es dudar si fue la debilidad de la mujer que se rindió a su fuerza superior o, simplemente, si ella se inclinó a su favor. Las mujeres son, por lo general, lo suficientemente hábiles para dejar esta cuestión en duda. La inteligencia femenina responde, a este respecto, perfectamente a su constitución. Lejos de sentirse avergonzadas de su debilidad, se enorgullecen de ella; sus músculos tiernos no ofrecen resistencia: aparentan ser incapaces de cargar con los más pequeños bultos y se sonrojarían si se las considerase robustas y fuertes. ¿A qué se debe todo esto? No sólo a la intención de parecer delicadas, sino por hábil precaución. De este modo, se procuran una excusa de antemano y un derecho a ser débiles cuando lo consideran oportuno.»

He anotado este pasaje para que mis lectores no sospechen que he falseado el razonamiento del autor en beneficio de mis propios argumentos. Ya he afirmado que educar a las mujeres bajo estos principios fundamentales conduce a un comportamiento artificioso y lascivo.

La conclusión es justa si se supone que la mujer ha sido creada únicamente para dar placer y someterse al hombre. $Y$ si se demostrase que ése era su triste destino, debería entonces sacrificar cualquier otra consideración para rendirse al hombre con agrado y permitir que este deseo brutal de supervivencia se convirtiera en el resorte principal de todas sus acciones, para lo cual tendría que ajustar su carácter, ampliándolo o empequeñeciéndolo, sin tener en cuenta ninguna distinción física o moral. Pero si se demuestra, como pienso, que incluso los propósitos de esta vida, observándola en su totalidad, fueran la subversión de toda una serie de reglas prácticas elaboradas a partir de esta base innoble, entonces, permítaseme dudar que la mujer fue realmen-

${ }^{1}$ Pasaje ya citado en la página 83, capítulo III. Rousseau, Emilio, libro V.

2 iQué estupidez! 
te creada para el hombre. $Y$ aunque se alcen sobre mí acusaciones de irreligiosa y atea, declararé simplemente que si viniera un ángel de los cielos para decirme que la bella y poética cosmogonía de Moisés y los relatos de la caída del hombre eran literalmente ciertos, no podría creer lo que la razón me había dicho que es injusto que provenga del Ser Supremo. Y sin temor a enfrentarme con el Diablo, me atrevo a llamar a todo esto una alucinación de la razón, en lugar de dejar reposar la debilidad de mi desgraciado sexo sobre los hombros del primer seductor.

«Una vez demostrado», continúa, "que el hombre y la mujer no son ni deben constituirse con igual temperamento y carácter, se sigue que no deben ser educados del mismo modo. Deben, en efecto, actuar conjuntamente siguiendo las directrices de la naturaleza, pero no deben, sin embargo, conprometerse con las mismas tareas; la meta final de sus empeños deberá ser la misma, pero los medios de que se sirvan para llegar a ella y, en consecuencia, sus gustos e inclinaciones, han de ser distintos.»

«Cuando considero el destino peculiar de cada sexo, y observo sus inclinaciones o señalo sus deberes, todas las cosas concurren del mismo modo a delimitar un método específico de educación que se adapte lo mejor posible a cada uno de ellos. El hombre y la mujer fueron creados el uno para el otro, pero su dependencia mutua no es la misma. El hombre depende de la mujer en relación a sus deseos; la mujer del hombre tanto en relación a sus deseos como a sus necesidades. Nosotros podríamos subsistir mejor sin ellas, que ellas sin nosotros.»

«Por este motivo, la educación de las mujeres debiera ser siempre relativa a los hombres. Complacernos, sernos útiles, hacer que las amemos y estimemos, que nos eduquen cuando somos jóvenes y nos cuiden cuando seamos viejos, nos aconsejen, nos consuelen, para que así nuestras vidas sean fáciles y agradables; éstos son los deberes de las mujeres de todos los tiempos y para lo que debieran ser enseñadas durante la infancia. Tan pronto como dejemos de recurrir a tales principios, nos alejaremos ampliamente de las normas, y todos los preceptos que se les ofrezcan no contribuirán ni a su felicidad ni a la nuestra."

«Las niñas se aficionan a los vestidos desde su más tierna infancia. No contentas con ser bonitas, están deseosas de ser consideradas como tales, y vemos, por todos sus ademanes, que este pensamiento les obsesiona. Difícil- 
mente son capaces de entender lo que se les dice mientras no tengan la seguridad de saber lo que la gente con la que están hablando piensa de ellas. Esto mismo, experimentándolo indiscretamente con los muchachos, no obtiene los mismos resultados. Poco les importa lo que la gente piense de ellos si están seguros de que pueden proseguir con sus diversiones o juegos. Tiempo y disgustos cuesta adoctrinar a los muchachos en este principio.m

«Derive de donde derive esta primera lección sobre las muchachas, es sin duda muy buena. Como de alguna manera el cuerpo nace antes que el alma, nuestra primera ocupación debe ser cultivar el primero. Este orden es común a los dos sexos, pero el objeto de cultivo es distinto; en un sexo es el desarrollo de sus poderes corporales; eri el otro, el de sus encantos personales. La calidad de la fuerza o de la belleza no deben confinarse exclusivamente a un solo sexo, pero debe observarse un orden de preferencias. Las mujeres, en efecto, requerirán la fuerza suficiente que las permita moverse y actuar graciosamente, y los hombres necesitarán una cierta destreza que les cualifique para actuar con agilidad.»

«Los niños de ambos sexos poseen una gran cantidad de diversiones en común. Y deben tenerlas. ¿No tienen acaso muchas en común cuando son mayores? A este respecto, cada sexo tiene también un gusto particular. Los muchachos adoran los deportes, el ruido y la actividad: tocar el tambor, jugar a las peonzas, arrastrar sus carritos por todas partes. Las niñas, por el contrario, sienten afición por los utensilios de gracia y ornamento, tales como los espejos, las chucherías y las muñecas. Las muñecas son la diversión principal de las niñas y de ahí vemos que su gusto se encuentra totalmente adaptado a su destino. La parte física del arte de agradar está vinculada al vestido. $\mathrm{Y}$ esto es todo cuando los niños están capacitados para cultivar de ese arte.»

«Vemos aquí, por tanto, una propensión primaria firmemente asentada, que sólo necesitamos seguir y estimular. La pequeña deseará saber indudablemente cómo vestir a su muñeca, hacerle los lazos de las mangas, los volantes, los sombreros, etc. Para ello necesitará recurrir siempre a los mayores y será mucho más agradable para ella saber cómo hacérselo por sí misma. $\mathrm{Y}$ aquí tenemos un buen motivo para las primeras lecciones que se enseñan generalmente a las niñas y con las que no aparecemos como imponiéndoles una tarea, sino favoreciéndosela al instruirlas en algo que les es útil de una manera inmediata. $\mathrm{Y}$ de hecho, casi todas aprenden con desgana a leer 
y escribir, pero se manejan muy pronto con las agujas. Se imaginan a sí mismas ya adultas y piensan con placer que ello las habilitará para adornarse personalmente.»

Ciertamente, esto no es más que la educación del cuerpo. Pero Rousseau no es el único hombre que indirectamente ha dicho que la mera persona física de una mujer joven, sin intelecto, a no ser que la vivacidad se incluya bajo esa descripción, es muy agradable. En aras de la debilidad y de lo que algunos llaman belleza, se desprecia la inteligencia, y se obliga a las muchachas a sentarse silenciosas, jugar con muñecas y escuchar conversaciones estúpidas. Se insiste en el efecto del hábito como si fuera una indicación indudable de la naturaleza. Sé que la opinión de Rousseau era que los primeros años de la juventud debían emplearse en la educación del cuerpo, aunque a la hora de educar a Emilio se desvía de su plan. Con todo, la distancia que hay entre fortalecer el cuerpo, de lo que en gran medida depende la fuerza del intelecto, y proporcionarle sólo movimientos gráciles es enorme.

Conviene indicar que las observaciones de Rousseau fueron expuestas en un país en el que el arte del placer era refinado sólo para extraer la grosería del vicio. O bien él no se reencontró a sí mismo, o bien su apetito imperioso distorsionó las funciones de la razón; porque si hubiera sido de otro modo, no podría haber llegado a unas conclusiones tan crudas.

Los niños y niñas en Francia (especialmente las últimas) son educados para agradar, para saber cómo moverse y cómo regular su comportamiento externo; y ya a muy temprana edad, sus mentes están corrompidas por las advertencias mundanas y devotas de que se guarden de la inmodestia. Hablo de tiempos pasados. La multitud de confesiones que los chiquillos tenían que hacer y las preguntas que les hacían los sacerdotes - y hablo de hechos bien comprobados - fueron suficientes para imprimir un carácter sexual. Y la educación de la sociedad era la escuela de la coquetería y del artificio. A la edad de diez u once años, ¡qué va! a menudo mucho antes, las niñas empezaban a coquetear, y hablaban, sin que se las reprobara, de establecerse en el mundo con un buen marido.

Resumiendo, eran tratadas como mujeres casi desde que nacían y no escuchaban más que cumplidos en lugar de recibir instrucción. En este debilitamiento de la mente, se suponía que la naturaleza había actuado como una madrastra, cuando configuró esta segunda idea de creación, la de la mujer.

No estándoles permitido comprender, era, sin embargo necesario someterlas a algún tipo de autoridad independiente de la razón. Y para prepararlas a esta dependencia, Rousseau ofrece los siguientes consejos:

"Las niñas deben ser activas y diligentes, pero eso no es todo; desde muy temprano hán de ser propensas a saber contenerse. Esta desventura, en caso de que lo sea realmente, es inseparable de su sexo, y nunca se han librado de ella sino para soportar infortunios mayores. Deben someterse al 
decoro durante toda su vida, que es el freno más severo y más constante. Es necesario, por tanto, acostumbrarlas desde pequeñas a esta limitación, no sea que después les cueste demasiado caro. En lo que respecta a la supresión de caprichos, deben estar dispuestas a aceptar el deseo de los demás. Si, por ejemplo, les gusta estar siempre trabajando, hay que impulsarlas a que lo dejen de vez en cuando. Demasiada indulgencia las corrompe y pervierte con la disipación, la vanidad y la inconstancia, que son los vicios a los que son más propensas. Para prevenir estos abusos debemos enseñarlas, ante todo, a saber mantenerse en los límites debidos. La vida de una mujer modesta se reduce, debido a todas nuestras instituciones absurdas, a un perpetuo conflicto consigo misma. Pero esto es justamente porque de alguna manera deben participar en los sufrimientos que su sexo demoniaco nos ha causado."

¿Y por qué la vida de una mujer modesta es un perpetuo conflicto? Contestaría que porque este sistema concreto de educación lo hace así. La modestia, la temperancia y la abnegación son los vástagos más sensatos de la razón. Pero cuando se alienta a la sensualidad a expensas de la inteligencia, y se reprime a estos seres débiles con medios arbitrarios sometiéndolos continuamente a conflictos, deberíamos entonces abrir las puertas a unos horizontes más amplios para la actividad mental, y entonces sus instintos y sentimientos se gobernarían por pasiones y propósitos más nobles.

«El apego y la estimación comunes de una madre, y ni siquiera eso, el simple hábito, la convertirán en un ser querido por sus hijos, siempre que ella no haga nada en contra de ellos. Incluso la obediencia que ella les imponga, si va bien dirigida, aumentará su cariño en lugar de aminorarlo. Y esto es así porque ellas mismas perciben la dependencia natural de su sexo, y se sienten nacidas para la obediencia.»

Esto ya vuelve a plantear la cuestión. No sólo deshonra al individuo su servilismo, sino que hasta parece que sus efectos son transmitidos a la posteridad. Pero, considerando la gran cantidad de tiempo que las mujeres han sido sometidas, ¿no sorprende que algunas de ellas anhelen las cadenas y sean zalameras como perros de aguas? «Estos perros, observa un naturalista, «conservan en un principio sus orejas erguidas; pero la costumbre ha llegado a ser símbolo de belleza."

«Por la misma razón», añade Rousseau, «las mujeres tienen, o deben tener, muy poca libertad. Son capaces de darse gusto en exceso con lo que les está permitido. Son aficionadas a los extremismos, y se entusiasman más por sus juegos que los muchachos.»

La respuesta es muy simple. Los esclavos y el pueblo se han dejado llevar siempre por los mismos excesos cuando conseguían aflojar el lazo de la autoridad. La curvatura de un arco se retira con violencia cuando la mano que lo sostenía firmemente se relaja de pronto. Y la sensualidad que es el juguete de los momentos superficiales, debe someterse a la autoridad y moderarse a través de la razón. 
«De esta contención habitual resulta», continúa, «la docilidad que las mujeres adoptan durante toda su vida, ya que permanecen constantemente sometidas a los hombres o a las ideas de la humanidad. La primera cualidad y la más importante de una mujer es la benignidad o la suavidad de temperamento: habiendo sido creadas para obedecer a un ser tan imperfecto como es el hombre, a menudo lleno de vicios y siempre de defectos, deben aprender con tiempo a sufrir las injusticias y aguantar los insultos de su marido sin rechistar. Esta disposición mansa no es por el bien del marido, sino por el suyo propio. La malignidad de las mujeres sólo les sirve para agravar sus infortunios, y mantener la mala conducta de sus maridos. Pueden percibir claramente que por esos medios no ganarán la superioridad.»

Creadas para vivir con un ser tan imperfecto como es el hombre, deben aprender, utilizando sus facultades, la necesidad de la paciencia; pero todos los sagrados derechos de la humanidad se violan al insistir en la obediencia ciega, a no ser que los derechos más sagrados de la humanidad sólo pertenezcan al hombre.

Aquel que pacientemente soporte la injusticia y aguante los insultos en silencio, se convertirá muy pronto en un ser injusto, incapaz de discernir entre lo correcto y lo erróneo. Además, niego este hecho; no es éste el camino para formar o mejorar el temperamento. Los hombres, como sexo, poseen mejor temperamento que las mujeres porque se ocupan de tareas que interesan tanto a la cabeza como al corazón. Y la estabilidad de la cabeza proporciona una temperatura saludable al corazón. La gente sensual raramente posee un buen temperamento. La formación del temperamento es el trabajo frío de la razón cuando, en el transcurso de la vida, lo va mezclando con artificios alegres y elementos vibrantes. Nunca he conocido una persona débil o ignorante que tuviera buen temperamento, a pesar de que la docilidad y el buen humor que el miedo imprime al comportamiento, obtengan ese nombre. Digo comportamiento porque la mansedumbre genuina nunca alcanzó al corazón ni a la mente, a menos que sea como efecto de la reflexión; y este simple sometimiento produce numerosos caracteres corrompidos en la vida doméstica: lo admitirán muchos hombres sensatos que han encontrado en estas criaturas irritables unas compañeras muy problemáticas.

«Cada sexo», argumenta más adelante, «debiera preservar su tono y maneras peculiares; un marido manso puede convertir a su mujer en un ser impertinente. Pero la disposición mansa de la mujer siempre hará retornar la razón al hómbre, a menos que éste sea un animal salvaje, y pronto o tarde triunfará sobre él.»

Quizá puede tener a veces este mismo efecto la templanza de la razón. Pero el miedo miserable siempre inspira desprecio. Y las lágrimas sólo tienen sentido cuando resbalan sobre unas mejillas justas.

¿De qué materiales puede nutrirse un corazón que sea capaz de enternecerse cuando se ve insultado y en lugar de rebelarse contra la injusticia, 
besa el látigo? Es injusto deducir que sus virtudes se basan en el egoísmo y en la estrechez de miras, porque ¿quién es capaz de acariciar a un hombre, con verdadera suavidad femenina, en el mismo instante en que él la trata tiránicamente? La naturaleza jamás dictó la falta de sinceridad. $Y$ aunque pudiera considerarse virtuoso algún acto de dependencia como éste, la moralidad se difumina cuando alguna de las partes descansa sobre la falsedad. Pero esto son meros recursos, y los recursos sólo son válidos en el momento.

Que el marido se guarde de confiar demasiado implícitamente en esta obediencia servil porque, si su mujer puede acariciarle con encantadora dulzura cuando está enfadada, o cuando debiera estarlo (a no ser que el desprecio haya ahogado su efervescencia natural) puede hacer perfectamente lo mismo después con su amante. Todo esto no es más que la antesala del adulterio; o ¿podría todo el miedo del mundo, o el temor al infierno, reprimir su deseo de complacer a otros hombres cuando ya no puede complacer a su marido? ¿Qué sustítuto puede encontrarse para un ser que sólo ha sido creado por la naturaleza y la artificiosidad para complacer al hombre? ¿Qué recompensa puede ofrecérsele? ¿Por dónde puede buscar un empleo saludable? ¿Dónde puede encontrar la capacidad de decisión suficiente para comenzar a investigar, cuando sus hábitos se hallan anquilosados y la vanidad ha dominado su mente durante largo tiempo?

Pero este moralista parcial recomienda sistemática y plausiblemente todas las astucias.

«Las hijas deben ser siempre sumisas; pero sus madres no han de ser inexorables. Para hacer a una persona tratable, no se la debe hacer infeliz; para hacerla modesta, no ha de convertírsela en estúpida. Al contrario, no me disgustaría que se la permitiera valerse de alguna artimaña para librarse de la necesidad de obedecer, aunque no así para eludir el castigo. No es necesario hacer'e su dependencia molesta, basta con hacérsela sentir. La sutiliza es un talento natural de su sexo. $\mathrm{Y}$ como estoy convencido que todas sus inclinaciones naturales son justas y buenas en sí mismas, soy de la opinión de que debiera ser cultivada tanto como las otras. Es un requisito para prevenir su abuso.»

«Sea lo que sea, es justo», deduce a continuación triunfalmente. Concedido. Es probable que nunca un aforismo haya contenido una afirmación más paradójica que ésta. Respecto a Dios, es una solemne verdad. El - hablo reverentemente - observa toda la realidad de una sola vez y contempla sus proporciones justas en las entrañas de los tiempos. Pero el hombre, que sólo puede examinar partes inconexas, encuentra muchas cosas equivocadas. $Y$ es parte del sistema y por lo tanto justo que se esfuerce en modificar lo que se le aparece como erróneo, aunque al mismo tiempo se incline ante la sabiduría de su Creador y, respetando la oscuridad, pretenda alejarla de sí.

La conclusión que sigue es correcta, suponiendo que llegara a pronunciarse este principio. «La superioridad de sus ardides, típicos del sexo feme- 
nino, es una compensación justa a su inferioridad física. Sin ella, la mujer no podría ser la compañera del hombre, sino su esclava; y gracias a este arte superior y a su ingenio, preserva su igualdad y le regula a la vez que ama obedecerle. La mujer tiene todo en contra suya, tanto nuestras propias faltas, como su timidez y su debilidad; no tiene nada a su favor más que la sutileza y la belleza. ¿No es razonable por tanto que cultive ambas?" La grandeza de espíritu no puede nunca anidar en los disimulos y las artimañas. No tengo intención de retroceder sobre palabras cuyo significado directo es la mentira y la falsedad, y me contentaré con observar que si cualquier tipo de sociedad se construye de tal modo que se haga necesaria una educación basada en reglas no estrictamente deducibles de la verdad, la virtud es entonces cuestión de costumbre. ¿Cómo pudo Rousseau atreverse a afirmar, tras haber dado este consejo, que el objetivo de ambos sexos sería el mismo al final de la existencia, cuando sabía perfectamente que la mente, formada según sus propósitos, se expande por inmensos panoramas, alejándose de los pequeños porque si no, ella misma se resumiría en muy poco?

Los hombres poseen mayor fuerza corporal que las mujeres; pero si no fuera por unos conceptos equivocados de la belleza, las mujeres adquirirían fuerza suficiente que las capacitase para ganar su propia subsistencia, que es la verdadera definición de independencia, y podrían soportar todas las inconveniencias y esfuerzos corporales que son requisito previo para fortalecer la mente. Que se nos permita, por tanto, llegar a la perfección del cuerpo practicando los mismos ejercicios que los muchachos, no sólo durante la infancia, sino también durante la juventud, y entonces podremos conocer realmente hasta dónde llega la superioridad natural del hombre. Porque ¿qué razón o virtud puede esperarse de una criatura cuando se descuida el tiempo de siembra de la vida? Ninguna. No en vano los vientos celestiales esparcieron sobre los barbechos multitud de fértiles semillas.

«La belleza puede adquirirse gracias al vestido, y la coquetería no es un arte que se alcance pronto ni con celeridad. Sin embargo, mientras las niñas son todavía jóvenes, están capacitadas para estudiar maneras agradables, una bella modulación de la voz, un talante y un comportamiento complaciente; y a la vez, pueden aprovechar las ventajas de saber adaptar con gracia sus miradas y actitudes a la ocasión, el lugar y el momento. Sus estudios, por tanto, no debieran reducirse únicamente a las agujas y la costura, ya que pueden desarrollar otros talentos cuya utilidad es manifiesta.»

«Por mi parte, educaría a una joven inglesa en el cultivo de sus agradables talentos, para complacer a su futuro marido, con tanto cuidado y asiduidad como un joven Circasio cultiva a sus jóvenes para que ingresen en el harén de un rajá del Oriente.»

Para rebajar a las mujeres a algo absolutamente insignificante, añade: «La lengua de la mujer es mucho más voluble. Habla más, con mayor disposición y gracia que el hombre; se la acusa de hablar mucho más, pero si es 
así, estaría en verdad muy dispuesto a convertir este reproche en un cumplido. Sus labios y sus ojos experimentan la misma vivacidad y esto es así por la misma razón. Un hombre habla de lo que conoce, una mujer de lo que le gusta. El uno requiere conocimientos, la otra gusto; el objeto principal de conversación de un hombre debiera versar sobre lo que es útil, el de una mujer sobre lo que es agradable. Sus discursos, distintos, no deben tener nada en común más que la verdad.»

«No debemos, por tanto, reprimir las charlas de las muchachas, aunque sí debemos hacerlo con las de los muchachos, preguntándoles severamente ¿qué pretendes con tus conversaciones?, y con esta otra que no es menos difícil de responder, ¿cómo serán recibidas tus palabras? Durante la infancia, como todavía no son capaces de discernir lo bueno de lo malo, deberían observar como regla, no decir nunca nada que pudiera resultar desagradable a quienes se dirigen. Lo que se deduce de esta regla, que es la más difícil, es que siempre deben subordinarse a lo anterior, esto es, no hablar nunca con falsedad ni decir una mentira.» Desde luego se requiere una gran habilidad para dominar de este modo la lengua, y lo cierto es que tanto hombres como mujeres la utilizan en demasía. QQué pocos hablan lejos de la exhuberancia del corazón! Son tan pocos que yo, que amo la sencillez, renunciaría de corazón a la buena educación por una cuarta parte de la virtud que se ha sacrificado en aras a una cualidad equívoca, que a lo mejor sólo era el barniz de la virtud.»

Pero, completemos el boceto. «Es fácil concebir que, si no tienen capacidad para formarse ninguna noción verdadera de la religión, estas ideas deben estar muy encima de las concepciones de las muchachas. Y por esta misma razón, comenzaría a hablarles antes de este asunto, porque si tuviéramos que esperar a que adquirieran capacidad para discutir metódicamente tales profundos asuntos, correríamos el riesgo de no hablarles en su vida de esta materia. La razón en las mujeres es una razón práctica, que las capacita para descubrir hábilmente los medios para alcanzar un fin concreto, pero nunca las hará capaces de descubrirlo en sí mismo. Las relaciones sociales entre los sexos son sin duda verdaderamente admirables: de su unión resulta una persona moral, a la que la mujer habrá aportado sus ojos y el hombre sus manos, con recíproca independencia los unos de las otras; esto es, que la mujer conoce lo que ve gracias al hombre y él lo que debe hacer gracias a la mujer. Si la mujer recurriera a los primeros principios como hace el hombre, y el hombre estuviera capacitado para formar parte de sus minutiae como la mujer, vivirían en discordia perpetua porque una cosa es independiente de la otra, y su unión no podría subsistir. Pero en la armonía presente que habrá de manera natural entre ellos, sus diferentes facultades tienden hacia un mismo fin: es difícil decir cuál de los dos impulsa más a éste: cada uno sigue el impulso del otro; cada uno es obediente, y los dos son maestros.» 
«Como la conducta de la mujer está subordinada a la opinión pública, su fe en asuntos de religión debiera someterse a la autoridad. Cada niña tendrá que tener la misma religión que su madre, y cada esposa la misma que su marido porque, aunque tal religión fuera falsa, esta docilidad que induce a la madre y a la bija a someterse al orden de la naturaleza aleja, a la vista. de Dios, la criminalidad de su error ${ }^{3}$. Como no tienen capacidad de juzgar por sí mismas, deben aceptar la decisión de sus padres y maridos con tanta confianza como las de la Iglesia.»

«Como la autoridad debe regular la religión de las mujeres, no es tan necesario explicarles las razones de su creencia como establecer los dogmas que tienen que creer: porque el credo que sólo presenta ideas oscuras a la mente, es fuente de fanatismo; y aquello que presenta necedades conduce a la infidelidad.»

Parece que la autoridad absoluta e incontrovertida subsiste por todas partes: ¿No es esto una apropiación directa y exclusiva de la razón? Los derechos de la humanidad se han confiado, de este modo, a los varones desde Adán hasta nuestros días.

Rousseau llevará todavía más lejos su aristocracia del hombre, ya que insinúa que reprobaría a aquellos que porfían en dejar a la mujer en el estado de la más profunda ignorancia, si no fuera necesario, en orden a preservar su castidad y justificar la elección del hombre a los ojos del mundo, inculcarla ciertos conocimientos sobre los hombres y las costumbres que producen las pasiones humanas. Además, podría propagar su inteligencia en casa, sin que se la considerase menos voluptuosa e inocente, excepto, claro, durante su primer año de matrimonio, que debiera emplearlo en vestirse como Sofía. «Su vestido es extremadamente modesto en apariencia, pero de hecho lleno de coquetería: no hace exhibición de sus encantos, sino que los disimula. Pero al ocultarlos sabe cómo impresionar vuestra imaginación. Cualquiera que la vea dirá: he aquí una mujer modesta y discreta. Pero mientras estéis cerca de ella, vuestros ojos y vuestras inclinaciones divagarán sobre toda su figura y no podréis apartaros; y concluiréis que cada prenda de su vestido, tan simple como parece, sólo fue colocada de aquel modo para que, con vuestra fantasía, lo desbarataseis en piezas.» ¿Es esto modestia? ¿No es acaso antesala de la inmoralidad? De nuevo, ¿qué opinión vamos a formarnos de un sistema de educación, en el que el autor dice de su heroína «para ella, hacer las cosas bien no es más que un asunto secundario; lo principal es hacerlas con claridad?"

Secundarias son, de hecho, todas sus virtudes y cualidades porque, en

3 ¿Cuál sería la consecuencia de esto si casualmente la opinión de la madre y la del marido no concordasen? A una persona ignorante no se la puede razonar su error, y cuando se la persuade para que abandone un prejuicio por otro, su mente se perturba. Puede darse el caso, también, de que el marido no tenga ninguna religión que enseñarle, en cuyo caso ella se encontrará con la gran necesidad de un sostén para su virtud, independientemente de consideraciones mundanas. 
lo relativo a la religión, hace que sus padres la acostumbren de este modo a la sumisión. "Tu marido te instruirá en el momento oportuno.»

Después de encadenar la mente de la mujer, y para que este hecho parezca justo, no la abandona en una laguna absoluta de conocimientos, sino que la aconseja meditar sobre lo que un hombre reflexivo no puede sincerarse en su compañía, cuando está cansado de acariciarla. ¿Qué puede meditar sobre la persona a la que debe obedecer? ¿Y no sería un refinamiento cruel abrir su mente sólo para hacerle visible la oscuridad y la miseria de su destino? Pero aún estas consideraciones son sensatas. El lector puede opinar sobre la consistencia de lo que acabo de decir para tener una visión justa del problema.

«Ellas, que pasan todas sus vidas amasando el pan de cada día, no tienen ideas más allá de sus ocupaciones o sus intereses. Esta ignorancia no es perjudicial ni para su integridad ni para su moral; a menudo les es útil. A veces, gracias a la reflexión, nos vemos inducidos a capitular de nuestro deber y terminamos por legar una jerga de palabras al cuarto de los trastos. Nuestra propia conciencia es el filósofo más inspirado. No hay necesidad de familiarizarse con las oficinas de Tully para hacerse un hombre de bien. Y quizá la mujer más virtuosa del mundo es la que menos familiarizada está con la definición de virtud. Pero no es menos cierto, sin embargo, que una inteligencia cuitivada sólo puede rendir a la sociedad afabilidad. Y es una realidad que un padre de familia, al que le gusta su hogar, se vea obligado a encerrarse en sí mismo y no tener a nadie alrededor con quién compartir sus sentimientos.

Por lo demás, ¿de qué modo podría educar a sus hijos una mujer incapaz de reflexionar? ¿Cómo podría inclinarles hacia aquellas virtudes con las que no está familiarizada y aquellos méritos que desconoce? Ella sólo puede calmarles o regañaries; hacerlos insolentes o tímidos. Los convertirá en mequetrefes formales o en zopencos ignorantes, pero nunca podrá hacerlos afables. ¿Cómo podría, en efecto, si su marido no está siempre a su lado para darle sus razones? Cuando están juntos crean un ser moral. Un deseo ciego, «ojos sin manos», recorrerá un camino muy corto. Y tal vez, debiera emplear su, razón abstracta, que debiera reunir los elementos dispersos de su razón, en elegir el vino apropiado, o discutir qué salsas son las más convenientes para acompañar un guiso de tortuga. $O$, en un intento más profundo sobre una mesa de juego, podría apostar su fortuna esparciendo sus ideas, y dejando todas las minutiae de su educación a su compañero, o arriesgarse.

Pero suponiendo que una mujer ha de ser bella, inocente y tonta para ofrecerse a un compañero más atractivo e indulgente. ¿Para qué se sacrifica su inteligencia? ¿Y para qué es necesaria toda esa preparación, de acuerdo con el relato del propio Rousseau, de convertirla en amante de su marido durante un tiempo tan breve? Porque ningún hombre ha insistido más en la naturaleza pasajera del amor. Así dice el filósofo: «Los placeres sexuales son pasajeros. El estado habitual de los efectos siempre se diluye con su 
gratificación. La imaginación, que adorna el objeto de nuestros deseos, se difumina en el goce. Exceptuando al Ser Supremo, nada es más bello que aquello que es ideal.»

Pero vuelve de nuevo a sus ininteligibles paradojas cuando arenga a Sofía: «Emilio, al convertirse en tu marido se transforma en tu maestro y reclama tu obediencia. Tal es la orden de la naturaleza. Sin embargo, cuando un hombre se casa con una mujer como Sofía, ella debe dirigirle. Esto concuerda también con la orden de la naturaleza. Se trata, por tanto, de ofrecer su autoridad sobre tu sexo como tú se la ofreces sobre su corazón. Te puede costar, quizá, algún sacrificio desagradable, pero tendrás la certeza de mantener tu imperio sobre él si eres capaz de preservarlo sobre ti misma. Me consta que lo que acabo de decir, este difícil intento, no sobrepasa tu coraje.»

«Si tienes a tu marido constantemente a tus pies, mantenlo a cierta distancia de tu persona. $Y$ si sabes cómo hacer tus favores raros y valiosos, mantendrás durante largo tiempo tu autoridad en el amor. $Y$ así, puedes emplear las artes de la coquetería al servicio de la virtud y las del amor al servicio del amor.»

Terminaré mis extractos con una descripción justa de la pareja adecuada. «Y de este modo, no debes imaginarte que estas gestiones bastan siempre. Cualesquiera que sean las precauciones tomadas, el placer rebajará gradualmente los límites de la pasión. Pero cuando el amor ha perdurado todo lo posible, se reemplaza por un hábito placentero, y a los viajes de la pasión sucede el enlace de una confianza mutua. Los niños a menudo forman un lazo permanente entre las personas casadas, más incluso que el amor en sí. Cuando dejes de ser la amante de Emilio, continuarás siendo su mujer y su amiga, serás la madre de sus hijos» ${ }^{4}$.

Observa certeramente que los hijos forman una unión más permanente entre la gente casada. La belleza, afirma, no será valorada, ni siquiera advertida, hasta que la pareja no hay vivido seis meses junta. La gracia artificial y la coquetería se desvanecerán también frente a los sentimientos. ¿Por qué, dice entonces, una niña ha de ser educada para un marido con el mismo celo que si fuera para un harén oriental?

Apelaré ahora al buen sentido de la humanidad para saber si el objeto de la educación que prepara a las mujeres para que sean esposas virtuosas y madres sensatas, a partir del embelesamiento de la razón y la inmoralidad refinada -el método plausiblemente recomendado en el boceto anterior-, es el que mejor se ha estudiado para alcanzar aquellos fines. ¿Se admitirá que el camino más seguro para hacer a una esposa virtuosa es enseñarle el ejercicio de las mañas descocadas de una amante, a las que se denomina co. quetería virtuosa en boca de este sensualista que ya no puede paladear los

* Rousseau, El Emilio. 
encantos de la sinceridad sin artificios, o saborear el placer que resulta de la dulce intimidad, cuando la confianza no se confronta con la sospecha y se hace interesante gracias a la razón?

El hombre que se contenta viviendo con una mujer bella y servicial, sin opiniones, pierde el gusto de los placeres más refinados en medio de gratificaciones voluptuosas; nunca puede sentir la plácida satisfacción de ser amado por aquella que le comprende, que refresca su corazón abrasado como un rocío silencioso y celestial. En el mundo de la mujer el hombre está solo, a menos que disminuya en brutalidad. «El encanto de la vida», dice un serio y filosófico razonador, es «la simpatía; nada nos agrada más que observar en otros hombres un sentimiento de compañerismo con todas las emociones que crecen en nuestro propio pechom.

A tenor del razonamiento por el que se les oculta a las mujeres el árbol de la ciencia, todo, los mejores años de la juventud, las ventajas que proporciona la edad, las esperanzas racionales en el futuro, todo se sacrifica para hacer de la mujer un objeto de placer durante un breve tiempo. Además, ¿cómo podría Rousseau esperar que fueran virtuosas y constantes cuando no admitía la razón como fundamento de la virtud, ni la verdad como objeto de sus preguntas?

Pero todos los errores de Rousseau parten de la sensualidad y las mujeres están muy dispuestas a perdonar la sensualidad a sus encantos. Cuando razonó, se hizo desapasionado y la reflexión inflamó su imaginación en lugar de iluminar su inteligencia. Incluso sus virtudes se descarriaron aún más lejos porque, nacido con una constitución sensual y vitalmente fantasioso, la naturaleza le condujo hacia el otro sexo con tal gusto que cayó en la lascivia. Si hubiera dado paso a sus deseos, el fuego se habría extinguido de manera natural, pero la virtud y su tipo romántico de naturaleza le hicieron asumir la abnegación; sin embargo, cuando el miedo, la delicadeza y la virtud le reprimieron, dio rienda suelta a su imaginación, y, volviendo sobre las sensaciones que la imaginación fortalecía, las trazó con los colores más resplandecientes y las sumergió en lo más profundo de su alma.

El entonces buscó la soledad, no para dormir junto al hombre natural, o investigar sosegadamente las causas de las cosas bajo la sombra en la que Isaac Newton se abandonaba a la contemplación, sino para dar rienda suelta a sus sentimientos. Y pintó con tanto calor aquello que él sentía con fuerza, que, interesando el corazón e inflamando la imaginación de sus lectores en proporción a la amplitud de su fantasía, llega a pensar que sus mentes se convencen cuando lo único que sucede es que simpatizan con un escritor poético, el cual presenta hábilmente los objetos del sentido sombreados de la manera más voluptuosa o tenuemente velados, y de esta forma, haciéndonos creer que razonamos mientras realmente estamos soñando, se asientan conclusiones erróneas en nuestra mente.

¿Por qué la vida de Rousseau se dividió entre éxtasis y miseria? Sólo 
puede responderse que la efervescencia de su imaginación produjo ambas; pero si hubiera habido posibilidad de que su fantasía se enfriase, es muy posible que hubiese adquirido mayor fuerza de mente. Es más, si el fin de la vida es educar la parte intelectual del hombre, todo respecto a él es correcto; si la muerte no le hubiera conducido a un escenario de acción más noble, es probable que habría disfrutado en la tierra más igualadamente, y que habría sentido las sensaciones tranquilas del hombre natural, en lugar de prepararse para otro estadio de existencia alimentando las pasiones que agitan al hombre civilizado.

Pero ipaz a sus sombras! No me peleo con sus cenizas, sino con sus opiniones. Lucho solamente contra la sensibilidad que le condujo a degradar a la mujer haciéndola ser una esclava del amor.

«... Cursed vassalage,

First idolised till love's bot fire be o'er,

Then slaves to those who courted us before» Dryden ${ }^{5}$.

Permitámonos, queridos contemporáneos, superar estos prejuicios estrechos. Si la sabiduría es deseable en sí misma, si lo es la virtud, para merecer tal nombre, debe basarse en el conocimiento; que se nos permita intentar fortalecer nuestras mentes a través de la reflexión hasta que nuestras cabezas lleguen a nivelarse con nuestros corazones; que se nos permita no limitar todos nuestros pensamientos a las bonitas ocurrencias del día, o nuestro conocimiento a una amistad con los corazones de nuestros amantes o nuestros maridos; permitid, en cambio, que la práctica de cada deber se subordine a aquel deber grandioso de mejorar nuestras mentes, y preparar nuestros afectos para un estadio más sublime. Guardaos entonces, amigos míos, del sufrimiento del corazón que se impresiona por cualquier accidente trivial; las cañas se mecen con la brisa y mueren anualmente, pero el roble se mantiene firme y durante años y años se enfrenta a las tormentas.

$\mathrm{Si}$, en efecto, sólo fuimos creados para desprendernos de nuestras horas y morir, entonces, que se nos permita perdonar la sensualidad y reírnos de la severidad de la razón. Pero jay!, incluso entonces buscaríamos la fortaleza de la mente y del cuerpo, y la vida se perdería en placeres desapasionados o en una tediosa languidez.

Pero este sistema de educación, que seriamente desearía verlo puesto en práctica, parece presuponer lo que nunca debe darse por supuesto, esto es, que la virtud nos escuda de los accidentes de la vida y que la Fortuna, quitándose de encima sus ropajes, sonreirá a una joven bien educada y concederá su mano a un Emilio o un Telémaco. Porque, por el contrario, el premio que la virtud reserva a sus devotos se limita, naturalmente, a sus propios

5 ¡Maldito vasallaje! Primero fuimos idolatradas hasta que la llama del amor se extinguió; después esclavas de aquellos que antes nos cortejaran (N. D. T.). 
corazones. Y a menudo deben contentarse con las ocupaciones más vejatorias del mundo, y soportar los vicios y los caracteres de aquellos por quienes nunca podrán sentir una amistad.

$\mathrm{Ha}$ habido muchas mujeres en el mundo que, en lugar de haber tenido ocasión de apoyarse en la razón y la virtud de sus padres y hermanos, han tenido que fortalecer sus propias mentes luchando contra sus vicios $y$ locuras; que nunca se han encontrado a un héroe bajo la figura del marido; que, pagando la deuda que les debía la humanidad, pudieron arriesgarse a hacer retornar la razón a su estado natural dependiente y restaurar las prerrogativas usurpadas, es decir, alzarse por encima de las opiniones de los hombres.

\section{PARTE IV}

No pretendo aludir a todos los autores que han escrito sobre el tema de las costumbres femeninas, ya que, en general, todos han escrito en la misma línea y sería dar vueltas sobre lo ya conocido; pero, al atacar las cacareadas prerrogativas del hombre, a las que categóricamente podemos denominar como el cetro de hierro de la tiranía y el pecado original de los déspotas, me declaro en contra de todo poder basado en prejuicios, por muy nimios que éstos parezcan.

Si la sumisión que se exige se basa en la justicia, no hay necesidad de recurrir a un poder más elevado porque Dios es la justicia en sí misma. Permítasenos entonces, como hijas que somos de los mismos padres, y si el hecho de haber nacido más tarde no nos convierte en hijas bastardas, razonar todos juntos y aprender a someternos a la autoridad de la razón cuando su voz se deje oír con claridad. Pero si se llegara a demostrar que este trono de privilegios sólo descansa sobre una masa caótica de prejuicios, que carecen de un principio inherente de orden que los mantenga con coherencia -0 que descansa sobre un elefante, o una tortuga e incluso sobre los poderosos hombros de un hijo de la tierra- entonces, aquellos que se aventurasen a desafiar las consecuencias podrían escapar sin cometer infracción legal de ningún tipo y sin pecar contra el orden de las cosas.

Mientras que la razón eleva al hombre por encima de los animales y la muerte es rica en promesas, quienes no tienen confianza en sus propias fuerzas son sometidos solitariamente a una autoridad ciega. Son libres, iquién ansía ser libre! ${ }^{6}$. Aquel que puede gobernarse no tiene miedo a la vida; pero si se estima algo más que el respeto a sí mismo, ha de pagarse el precio hasta la última gota. La virtud, como cualquier cosa valiosa, ha de ser amada en sí misma, porque si no, no residirá en nosotros. No nos ofrecerá esa paz

\footnotetext{
- «Ese es el hombre libre, a quien la verdad hace libre» Cowper.
} 
que «rebasa el entendimiento» si uno sólo se sirve de ella para defender su reputación o si se la respeta con celo farisaico porque «la honestidad es la mejor política».

No se puede negar que el plan de vida que nos capacita para que podamos aportar algo de virtud y conocimiento al otro mundo es el que mejor está calculado para asegurar nuestra felicidad en el presente; no obstante, a pesar de que esto se admite universalmente sin discusión, es muy poca la gente que actúa de acuerdo con este principio. Los placeres o el poder del momento alejan estas convicciones grandiosas; y el hombre pacta la felicidad de un día y no la de toda la vida. Qué pocos, qué poquísimos poseen la prevención o la resolución suficiente para soportar una pequeña tentación momentánea, y evitar así una mayor más adelante.

Las mujeres en particular, cuya virtud ${ }^{7}$ se edifica sobre prejuicios mutables, raramente alcanza esta grandeza de espíritu; y de este modo, convirtiéndose en la esclava de sus propios sentimientos, puede ser fácilmente sojuzgada por los de los otros. ¡Hasta tal punto se ha degradado su razón, su nebulosa razón, que la emplea más en dar brillo a sus cadenas que en intentar hacerlas estallar en mil pedazos!

He oído con indignación argüir a mujeres en el mismo tono que los hombres y adoptar los mismos sentimientos que las embrutecen con toda la terquedad de su ignorancia.

Debo ilustrar mi aseveración con algunos ejemplos. La señora Piozzi, que a menudo repetía mecánicamente lo que no entendía, se expresa con el acento de la época de Johnson.

«No busques la felicidad en la originalidad; y teme el refinamiento de la sabiduría como si fuera una desviación de la locura.» De esta manera se dirigía dogmáticamente al joven casado. $\mathrm{Y}$ para aclarar este pomposo preámbulo, añade: «Te he dicho que los encantos de tu esposa no aumentarán, pero por favor, no le hagas sospechar nunca que disminuyen: Bien es sabido que una mujer perdonará mucho antes un insulto a su inteligencia que a su cuerpo; y ninguno de los dos vamos a contradecir esta afirmación. Todos nuestros talentos, todas nuestras artes, sirven para ganar y conservar el corazón del hombre, y ¿qué otra mortificación puede superar el desencanto de no obtener dicho fin? No hay reproche, por doloroso que sea, ni castigo severo que una mujer de espíritu prefiera no olvidar; y si es capaz de soportarlo sin protesta, esto prueba simplemente que pretende compensar los desaires de su marido con la atención de otros.»

La verdad es que éstos son verdaderos sentimientos masculinas. «Todas nuestras artes se emplean en ganar y conservar el corazón del hombre.» - ¿Y cuál es la conclusión? - si su persona caía en el olvido. (¿Y hubo alguna vez persona, por muy bien proporcionada que estuviera, que no fuera

' Entiendo este concepto en un sentido más amplio que la castidad o virtud sexual. 
despreciada?), entonces se consolaba esforzándose en complacer a otros hombres. ¡Bonita moralidad! Pero es así como se insulta a la inteligencia de todo el sexo femenino y se despoja a la virtud de sus bases comunes. Una mujer debe saber que su cuerpo no puede ser tan agradable a su marido como a su amante, y si se ofende con él, por ser una criatura humana, puede lamentarse también de perder su corazón como cualquier otra cosa estúpida. Y esta falta de discernimiento o esta cólera irracional demuestra que él no podría convertir la ternura que siente por su persona en cariño por sus virtudes o respeto por su inteligencia.

Cuando las mujeres comulgan y actúan en consecuencia con tales opiniones, sus inteligencias merecen, al menos, el desprecio y la maledicencia que los hombres, que nunca insultan a sus cuerpos, han proporcionado sutilmente a la mente femenina. $Y$ son los sentimientos de estos hombres educados, que no desean abrumarse con la mente, los que las mujeres adoptan sin pensarlo. Sin embargo, ellas debieran saber que la sola razón difamada de la mujer puede darle este pudor sagrado a su persona que permita que los afectos humanos - que siempre tienen una base aleatoria- sean tan permanentes como coherentes con el gran fin de su existencia: la obtención de la virtud.

La Baronesa de Staël habla el mismo lenguaje que la dama que acabo de citar, aunque con mayor entusiasmo. Casualmente cayó en mis manos su elogio de Rousseau, y sus sentimientos, los sentimientos de muchas de mi sexo, pueden servir de base para algunos comentarios. «Aunque Rousseau», observa, «se ha esforzado en prevenir a las mujeres de interferir en asuntos públicos y tomar parte brillante en el teatro de la política. ¡Cuánto ha hecho para su satisfacción al hablar de ellas! Si quiso privarlas de algunos derechos ajenos a su sexo. ¡Cuánto les ha restituido para siempre! $Y$ al intentar disminuir su infiuencia en las deliberaciones de los hombres. ¡Cómo ha restablecido sagradamente el imperio que poseen sobre sus felicidades! Ayudándolas a descender de un trono usurpado, las ha aposentado firmemente sobre aquel que la naturaleza les ha destinado. $\mathrm{Y}$ a pesar de que se llena de indignación cuando intentan parecerse a los hombres, su respeto a sus personas físicas linda casi en la adoración cuando se le acercan con todos los encantos, debilidades, virtudes y errores de su sexo." ¡Cierto! Porque nunca hubo sensualista que pagara mayor ferviente adoración al santuario de la belleza. Fue tan devoto, en efecto, en su respeto por la figura femenina que, exceptuando por razones obvias la virtud de la castidad, sólo deseó verla embellecida por encantos, debilidad y errores. Tenía miedo que la austeridad de la razón distorsionara el retozar del amor. El maestro prefirió tener a una esclava meretricia para mimarla que fuera totalmente dependiente de su razón y generosidad. No quería una compañera a la que debiera verse impulsado a apreciar, o una amiga a quien pudiera encargar la educación de sus hijos si la muerte les privase del padre antes de que hubiera podido terminar su 
sagrada tarea. Niega la razón de la mujer, la aleja del conocimiento y la mantiene aparte de la verdad; $y$, sin embargo, todo se le perdona porque «admite la pasión del amor». Se necesitaría bastante ingenio para demostrar por qué las mujeres necesitan mantenerse bajo tales obligaciones respecto a él para de este modo admitir el hecho del amor; cuando lo que está claro es que él lo admite sólo para su relajación y para la perpetuación de la especie. Pero se expresó apasionadamente y este poderoso hechizo hizo mella en la sensibilidad de una joven encomiasta. «Lo que significa» dice esta rapsoda «para las mujeres es que su razón se disputa el imperio con las razones de ellas, mientras que su corazón les pertenece enteramente a ellas.» No es un imperio, sino igualdad, lo que debieran pretender. $Y$ aun, si ellas desearan ampliar sus soberanías, no debieran confiar enteramente en sus figuras, porque la belleza puede ganar un corazón, pero no conservarlo, incluso cuando esté en pleno esplendor, a no ser que la mente las apoye con algunos atractivos, al menos.

Cuando las mujeres estén lo suficientemente preparadas para descubrir sus verdaderos intereses en gran escala, estoy segura de que estarán dispuestas a relegar todas las prerrogativas del amor, que no son mutuas, y hablar de ellas como prerrogativas secundarias, a cambio de la plácida satisfacción de la amistad y la tierna confianza de un cariño cotidiano. No asumirán ninguna actitud insolente antes de casarse para ceder abyectamente después; porque al esforzarse en actuar, en ambas situaciones, como criadas racionales, no serán arrojadas de un trono para sentarse en un taburete.

La señora Genlis ha escrito varios libros entretenidos para niños; y sus Letters on Education abordan muchas sugerencias útiles, de las que todos los padres sensatos ciertamente se valerán. Pero sus puntos de vista son estrechos y sus prejuicios tan fuertes como irracionales.

Pasaré por encima de su vehemente argumento en favor de los castigos porque me avergüenza pensar que un ser humano puede argüir con tanta vehemencia en un caso así, y haré sólo algunos comentarios sobre su absurda manera de hacer que la autoridad paterna suplante a la razón. Por todas partes inculca no sólo la sumisión ciega a los padres, sino a la opinión general del mundo ${ }^{8}$.

Cuenta la historia de un joven prometido a una joven de fortuna por deseo de su padre. Antes de que se llevara a cabo la boda, ella pierde su fortuna y se encuentra sola en el mundo, sin un amigo. El padre lleva a cabo las artimañas más infames para separar a su hijo de ella, y tan pronto

${ }^{8}$ Una persona no puede actuar en tal o cual forma aunque esté convencida de que actúa correctamente, porque algunas circunstancias equívocas pueden conducir al mundo a sospechar que actuaba por diferentes motivos. Esto no es más que sacrificar la sustancia por una sombra. Permitid a la gente contemplar sus propios corazones y actuar correctamente tanto como puedan juzgar, y podrán guardar pacientemente a que la opinión del mundo se aproxime. Es mejor ser dirigido por un motivo simple; y es que la justicia ha sido muy a menudo sacrificada a la propiedad, o dicho de otro modo, a las conveniencias. 
como el joven se percata de su villanía, sigue los dictados de su honor y se casa con ella. No le sobrevienen más que miserias porque, jen efecto!, se había casado $\sin$ el consentimiento paterno. ¿En qué tierra puede descansar la religión o la moralidad cuando se desafía a la justicia hasta tales extremos? Con la misma visión representa a una joven y distinguida mujer dispuesta a casarse con aquel que su madre desee recomendar. $Y$ al casarse finalmente con el joven escogido, no sintió ninguna emoción o pasión, porque esta niña tan bien educada no tuvo tiempo de enamorarse. ¿Es posible sentir mucho respeto por un sistema de educación que insulta de este modo a la razón y a la naturaleza?

Se suceden muchas opiniones similares en sus escritos, entremezcladas con los sentimientos que el honor crea en su cabeza y en su corazón. Sin embargo, se mezcla tal superstición en sus ideas religiosas y tal sabiduría mundana en su moralidad, que no permitiría a ninguna persona joven leer sus libros, a menos que pudiera después hablar sobre los temas tratados y clarificar las contradicciones.

La señora Chapone ha escrito sus cartas con tanto sentido común como desafectada humildad, y contienen tantas observaciones útiles, que sólo las mencionaré para pagar a esta valiosa escritora el tributo de mi respeto. No puedo, ciertamente, coincidir siempre con su opinión, pero la respeto siempre.

Justamente la palabra respeto me trae el recuerdo de la señora Macaulay. Es sin duda, la mujer de más talento que este país ha tenido nunca. $Y$, sin embargo, ha tenido que sufrir muriendo sin el debido respeto que hubiera debido pagarse a su memoria.

La posteridad será, sin embargo, más justa y recordará a Catherine Macaulay como un ejemplo de logros intelectuales que se suponían incompatibles con la debilidad de su sexo, que no se manifiestan pomposamente en su estilo, sino que éste aparece tan fuerte y claro como los significados que transporta.

No calificaré su inteligencia de masculina porque no admito una asunción tan arrogante de la razón, pero sostengo que pudo parecerlo, y que sus juicios, frutos maduros de un pensamiento profundo, fueron la prueba de que una mujer puede adquirir juicio en el sentido más extenso de la palabra. Poseyendo más penetración que sagacidad, más inteligencia que fantasía, escribe con soberbia energía y gran rigor argumental; sin embargo, su simpatía y su benevolencia proporcionan tanto interés a sus sentimientos, y tal ardor vital a sus argumentos, que obligan al lector a considerarlos ${ }^{9}$.

Cuando pensé por primera vez escribir estas notas, quise obtener la apro-

${ }^{9}$ Coincidiendo con la opinión de la señora Macaulay en las diferentes ramas de la educación, me remito a su valiosa obra, en lugar de anotar sus sentimientos para apoyar los míos propios. 
bación previa de la señora Macaulay, con un poco de aquella vivacidad adolescente que he debido reprimir toda la vida, pero pronto oí con la conciencia dolorida de una esperanza perdida y la gravedad de una pena que aún existe, que ella ya no estaba en el mundo. 
CRITICA DE LIBROS 